\title{
Decision support systems in forest management: requirements from a participatory planning perspective
}

\author{
Susanne Menzel • Eva-Maria Nordström • \\ Matthias Buchecker • Alexandra Marques • \\ Heli Saarikoski · Annika Kangas
}

Received: 18 June 2011 / Revised: 25 November 2011/Accepted: 24 January 2012/Published online: 14 February 2012

(C) Springer-Verlag 2012

\begin{abstract}
Participatory approaches and computerised tools such as decision support systems (DSS) represent conflicting tendencies in state-of the-art sustainable forest management. As a result, there may be considerable tension between these two developments in practice. The objective of this paper is to explore how participatory approaches and DSS could be brought together to improve planning processes and to explore how DSS could be adapted in their use or combined with other tools to enable successful participatory planning. From a review of the literature, we identified criteria related to successful participatory planning. From these criteria, we selected those a DSS can influence and created a short list of the criteria that could be used to evaluate participatory
\end{abstract}

Communicated by M. Moog.

S. Menzel $(\bowtie) \cdot$ M. Buchecker

Swiss Federal Institute for Forest, Snow and Landscape

Research, Economics and Social Sciences, Zürcherstrasse 111, 8903 Birmensdorf, Switzerland

e-mail: susanne.menzel@wsl.ch

E.-M. Nordström

Department of Forest Resource Management, Swedish

University of Agricultural Sciences, 90183 Umeå, Sweden

e-mail: eva-maria.nordstrom@slu.se

\section{A. Marques}

Instituto Superior de Agronomia, Universidade Técnica de Lisboa, Tapada da Ajuda, 1349-017 Lisboa, Portugal

H. Saarikoski

Environment Policy Centre, Finnish Environment Institute, 00251 Helsinki, Finland

A. Kangas

Department of Forest Sciences, University of Helsinki, P.O. Box

27, 00014 Helsinki, Finland processes where DSS are applied. The evaluation criteria with particular relevance for DSS that we identified are as follows: fairness, opportunity to influence outcome, quality and selection of information, cost-effectiveness, challenging status quo and fostering creative thinking, structured decision-making process, transparency, and independence and neutrality of process. We also scrutinised existing forest DSS and identified features that may enable DSS to address these criteria. The features of DSS we identified that may support participatory processes are as follows: group decision support, possibilities to include other values than timber production, flexibility of system to include non-traditional forest data and management options, and multi-criteria decision analysis tools. We argue that the DSS to be used should be assessed to clarify, how it can be used in the specific planning situation and how it should be complemented with other available and non-computerised tools.

\section{Introduction}

In recent decades, the focus of forest management has shifted. The dominant orientation of forest management towards optimising timber production, financial returns, and technical processes has gradually been replaced by a view of forests as sources of other benefits in addition to timber and profits, for example, biodiversity and recreation (Xu and Bengston 1997; Davis et al. 2001). This changing focus is connected with the development of sustainable forest management (SFM), which takes into consideration ecological and social as well as economic values (Hahn and Knoke 2010). At the United Nations Conference on Environment and Development in Rio 1992, a set of principles for SFM, the 'Forest Principles', was first adopted in line with general principles of sustainable development (UN 
1992). Following the Rio conference, several frameworks for criteria and indicators have been developed in forest policy processes to provide guidelines for evaluating and implementing SFM at the international and national levels (Castañeda et al. 2001; Hahn and Knoke 2010; The Montréal Process 2009). The increased involvement of stakeholders and the general public in forest planning accompanies SFM (Sheppard and Meitner 2005; Cubbage et al. 2007; Hahn and Knoke 2010). Thus, participatory planning, which relies on dialogue, deliberation, and public participation can be considered a standard component of state-of-the-art forest management.

At the same time, there has been an increase in the development of computerised tools and models in various scientific disciplines related to resource management (Matthies et al. 2007), including forestry. Historically, the forestry sector has had a stronger focus on decision support tools than other resource management sectors, such as conservation biology, presumably because of the greater emphasis on production in forestry.

Participatory approaches and computerised tools do not, however, guide resource management in the same direction; one might even argue that they represent conflicting tendencies and that there exists considerable tension between these two developments (Allen and Gould 1986). One of the fundamental differences between analytical and deliberative approaches is the conceptualisation of preferences. While decision analysts tend to see preferences as something stable that has to be elicited from the participants, advocates of deliberative approaches emphasise changes in preferences as the result of learning or consensus-building processes. Modellers also tend to represent a normal or Newtonian understanding of science, focusing on predictability and ifthen scenarios (Checkland 1981), whereas scientists who follow deliberative approaches might_according to a more recent understanding of the relationship between society and science-focus on uncertainties and question the fact-value dichotomy (Funtowicz and Ravetz 1993; Gibbons 1999; Nowotny et al. 2001).

We ask how these two strands-more deliberation and participation, on the one hand, and more advanced computerised tools and modelling, on the other-could be brought together to improve planning processes and their outcomes from an SFM point of view. More specifically, we ask how computerised tools and analytical approaches should be changed, adapted in their use, or combined with other features of the process so that they enable successful participatory planning.

In focussing on the integration of participatory methods with analytical tools, we deal with an innovative but not completely new topic. Over the last two decades, a number of studies of participatory forest planning in combination with multi-criteria decision (MCD) techniques have been published (Kangas et al. 1996; Kangas et al. 2001; Ananda and Herath 2003a, b; Laukkanen et al. 2004; Maness and Farrell 2004; Hiltunen et al. 2008; Hiltunen et al. 2009; Eyvindson et al. 2010; Nordström et al. 2010). In this study, we will build on the previous work on the participatory use of decision support systems (DSSs) in forest management. In particular, we will discuss the criteria for effective participation presented in the extensive literature (see Appendix 1) in the context of forest planning. Overall, we aspire to provide condensed insights from the social sciences for the development and application of technical tools to achieve good participatory forest planning with the support of DSSs.

To approach the question "How may deliberative and analytical approaches be better combined?" we turn to the literature on the evaluation of participation in natural resource management, which has evolved following the rise of participative planning processes. In this field, success criteria for public participation have been developed (e.g., Rowe and Frewer 2000; McCool and Guthrie 2001; Beierle and Cayford 2002; Blackstock et al. 2007). However, the identified success criteria are often theoretical or normative. Moreover, they originate from different theories, motivations, and contexts. Some evaluation criteria appear contradictory, and the empirical evidence is still ambiguous. Additionally, evaluation criteria have not yet been specifically reviewed to derive suggestions for specific groups of actors involved in forest-planning processes: those who are in charge of handling information, or project leaders who are in charge of integrating the analytical and deliberative aspects of the planning process.

Given these gaps in earlier research and our objective of examining the potential strengths and limitations of DSSs for enabling successful participation, we aim at

- identifying those criteria that are of particular relevance from the perspective of participatory planning and that have particular potential to be improved by the development of new and better decision support systems (DSSs).

- identifying DSS features with a positive effect on the evaluation criteria and reviewing some of the existing DSSs in Europe with respect to these targeted DSS features.

- discussing the contribution and limitations of these features for enabling good participatory planning processes.

\section{Conceptual framework, analysis, and material}

The first step, an important starting point for our review of success criteria in the participation literature, is to present our reflections on the concept of success. 
Conceptual framework-the notion of success

Participation may be undertaken for various reasons, depending on the context of the problem and the motivations of the actors involved. Three essentially different rationales have been used to describe different motivations for and perspectives on participation: the normative, substantive, and instrumental rationales (Fiorino 1989; Blackstock et al. 2007; Stirling 2008). According to the normative rationale, participation is a way to make the decision-making more democratic. From a normative perspective, furthermore, participation is an end in itself rather than a means to an end because participation may represent a process of empowerment through its support of individual and social learning. From the substantive perspective, participation is a means for producing better outcomes from a societal point of view by improving the overall understanding of the decision problem through the incorporation of multiple perspectives. Finally, the instrumental rationale asserts that participation may facilitate implementation and prevent conflict by improving the relations and understanding between stakeholders.

Depending on one's rationale or motivation for a participatory process, different outcomes reflect success. According to the conceptual distinction that Fiorino has proposed, conveners who are motivated by normative reasons see empowered citizens as an indicator of success; for advocates of the substantial perspective, a decision that includes the knowledge and perspective of many different stakeholders is successful; and actors who are motivated by instrumental reasons see the implementation of a project with little resistance from stakeholders as successful. This distinction also implies that adopting a 'participation perspective' does not necessarily imply subscribing to the normative rationale.

Drawing on the above-mentioned literature, we see success as a multidimensional concept. Accordingly, we recognise that trade-offs among success measures may well occur. Moreover, participants have been found to have different perceptions on what constitutes a successful process. They consider different and conflicting aspects as crucial for assessing a process as proper or successful (Wittmer et al. 2006) and would accordingly choose different evaluation criteria. For definitions of the key concepts considered in this paper, see Box 1.

\section{Selection of evaluation criteria}

To get a comprehensive view of the criteria related to successful participatory planning, we first reviewed the relevant literature (Appendix 2) and listed the 43 success criteria presented by various authors (Table 1). Second, we condensed the list by combining similar criteria (Table 2) and excluding others on various grounds. One reason for omitting criteria was that some criteria seemed too specific to the context of the investigation in which they were identified. Based on this consideration, we excluded, for example, 'willingness to isolate issue from national issues'. Some criteria, such as 'purposeful selection of group members', seemed too detailed on the operational level, and we omitted them for this reason. Other criteria could be placed in an existing category without considerable information loss. That is, they were illustrations of one of the existing categories and did not reflect new aspects of the problem. Examples of criteria that reflected existing categories are 'direct contact between the agency and the public' or the advice to 'make sure that the process was engaging'. We also excluded those criteria that we viewed as elements of the motivation underlying participatory decision-making processes and that were tightly linked to one of the three rationales, such as 'improved quality of decision'. Finally, we excluded effects that can only be expected to occur in the long term, such as 'institutional learning'.

In a third step, we selected the criteria that we consider relevant in the context of DSSs by utilising the definitions of criteria listed in Appendix 2. In this step, we excluded criteria on the grounds that we would not expect the scores on those criteria to reflect the quality of the design of a DSS. The selection process at this point was 'positive', not based on the exclusion of non-fitting criteria. That is, we selected a particular criterion if we believed, with good reason, that a DSS could influence that criterion. The specific reasons for choosing the eight criteria that we finally selected are presented in the results section.

In a fourth step, we looked at existing DSSs that have been developed and used in forest planning. For a general description of forestry DSSs, see Box 2. As a sample, we used those DSSs that we reviewed on the FORSYS wiki ${ }^{1}$ in December 2010; we found 60 DSSs. From the descriptions of the individual DSSs, we could identify five DSSs that had been used in participatory planning and three that had not. For the rest of the DSSs, the descriptions were not clear on this point, and some of these DSSs may have been used in participatory planning. In addition, we could identify five DSSs in the FORSYS wiki that contain features for multi-criteria decision analysis (MCDA). We also considered literature and our experiences in working with some of these DSSs to identify features that might enable successful participatory planning processes. The result of

\footnotetext{
1 The COST Action FP0804, Forest Management Decision Support Systems (FORSYS), aims at producing decision support guidelines for forest management planning problems. Information about the outcomes of the Action can be found at: http://fp0804.emu.ee/ wiki/index.php/Main_Page.
} 


\section{Box 1 Definitions}

The term public participation is understood as the "practice of consulting and involving individuals [who are not officially responsible] for a decision in the agenda setting, decision-making and policy-forming activities of organisations or institutions [which are officially] responsible for [decision and] policy development" (adapted from Rowe and Frewer 2004, p. 512)

By participants we mean members of interest groups, stakeholders (representatives of $\mathrm{CSO}^{2}$ s), representatives from different sectors or levels of government/public administration, and members of the general public (or 'unorganised' citizens). Other actors (directly or indirectly) involved in participatory processes are the initiator/convener (who might in many cases be the official responsible actor/agency), and the facilitator or mediator.

\section{Box 2 Forest DSS}

Forestry DSSs typically include models and methods by which the current status of different forest variables can be calculated based on measurements made. They also include a growth and yield simulator, which can be used to predict the consequences of different forest treatment scenarios (e.g., MELA, GAYA, Silva, Sibylla and others, see WIKI). With this sort of DSS, it is possible to carry out if-then types of analyses. The number and quality of variables varies from a few timber-production-oriented ones to a full array of variables that also describe the ecological and social aspects of forestry (e.g., Heureka, see WIKI). In addition, many forest DSSs nowadays include an optimisation tool, with which it is possible to select the 'best' alternative from among those considered based on some (mathematically defined) objective function and possible constraints (e.g., MELA, SIMO, Heureka). Some of the modern DSSs also incorporate the possibility of including local/ expert information and the preferences of decision-makers and/or participants in the system. The information can be produced/presented in different ways, from graphical forms (e.g., maps of social/ecological values) to mathematical multi-person utility functions. It can also be utilised in several ways, starting from the collection and storage of information on public preferences for the information of the responsible decision-maker to the support of (interactive) group decision-making (e.g., MESTA). However, the concept of DSS can also be understood in a wider sense to include all IT-based tools; these applications can be used to help in (forest) decision-making, starting from simple spreadsheet tools and databases.

this step was a list of features that enable DSSs to address the relevant evaluation criteria.

In the results section, we present the criteria that we have identified as relevant for the design and use of DSSs. We also present the features of existing forest DSSs that address these criteria, give reasons why we think these features are helpful in addressing the criteria, and show how common they are. In the discussion, we explain how we expect these features to enable successful participatory planning. We then spell out challenges to the broader fulfilment of these criteria through the features of DSSs. Finally, we suggest possibilities for complementing DSSs with non-computerised techniques.

\section{Results}

Criteria relevant to the evaluation of DSSs (tools) in participatory planning settings

In all, we identified 43 evaluation criteria. After some criteria were merged or omitted, 20 main evaluation criteria remained. These criteria are shown in Table 2. From this list, we selected the eight criteria having particular relevance for the design and use of DSSs. The grounds for our selection are explained below. The criteria are: fairness, the opportunity to influence outcome, the quality and selection of information, cost-effectiveness, challenging

${ }^{2}$ CSO_civil society organisation the status quo and fostering creative thinking, a structured decision-making process, transparency, and independence and neutrality of the process. We suggest that in terms of these criteria, a participatory process could benefit from the use of DSSs.

Considerations used to select the eight criteria particularly relevant to DSSs

A DSS may enhance the fairness of a process by providing participants access to the decision process, in particular by improving their understanding of the information that is used to reach a decision, and by giving participants the opportunity to state their preferences and to see what impact their statements might have on the outcome. A challenge associated with using DSSs is to make the tool understandable, and thereby acceptable, to the participants.

A DSS may enhance the opportunity to influence outcome because it allows the participants to have their preferences explicitly included in the system that supports the decision-making. One of the biggest challenges associated with DSSs is how to include different values, i.e., how to give participants the opportunity to bring in new values other than those related to forestry, such as scenic values or recreational values. A DSS may also contribute to improve the quality and selection of information because for this tool to be operational, the available information has to be compiled in a structured and clearly arranged way. 
Table 1 The 43 criteria that resulted from the review and first selection step

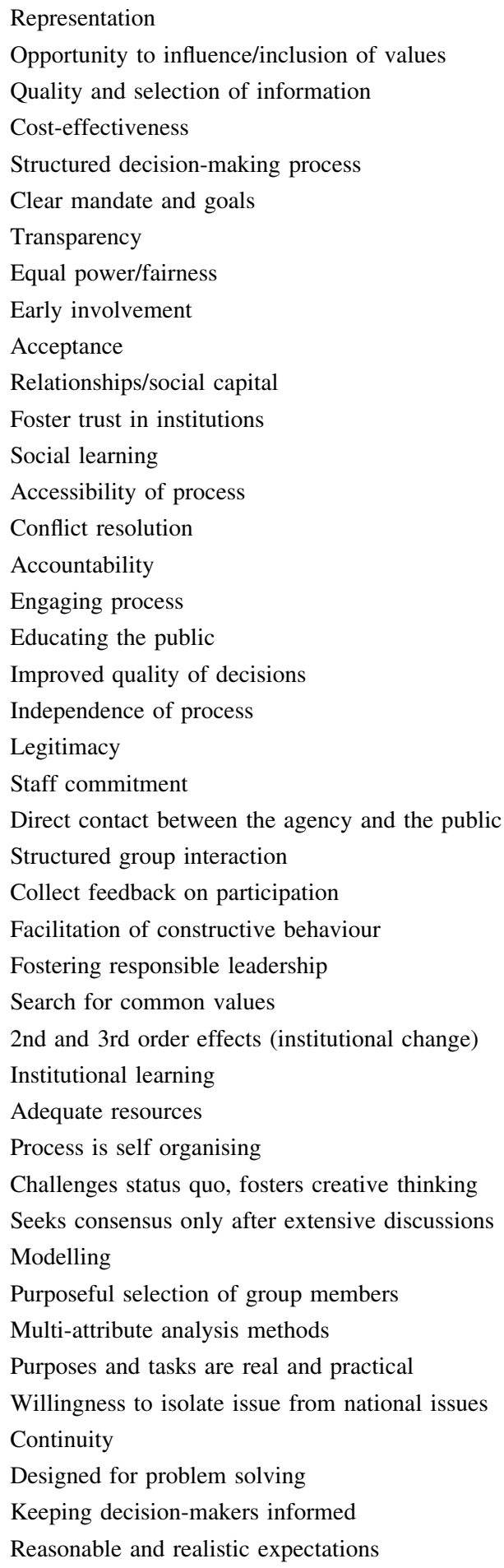

A DSS can help to illustrate the consequences of different actions accurately (e.g., the age distribution and species composition of a forest under certain management scenarios) and can thus help participants to identify the alternative that they actually prefer.
Table 2 Condensed list of evaluation criteria for participatory processes

Evaluation criteria

\section{Fairness}

Relationships and social capital building

Structured group interaction

Facilitation of constructive individual/group behaviour

Representation

Opportunity to influence outcome

Quality and selection of information

Cost-effectiveness

Accessibility of process

Adequate resources

Opportunity to influence process design

Challenging status quo and fostering creative thinking

Structured decision-making process

Clear mandate and goals

Transparency

Acceptance of outcome

Accountability

Independence and neutrality of process

Legitimacy

Search for common values

Bold are those criteria that are relevant in the context of DSS

A DSS can improve the cost-effectiveness of information handling if data are available in a form that the DSS can process and if expert knowledge and software are available (e.g., if the application of a DSS is part of a transdisciplinary research process). The process may be more effective, in particular, if the participants also trust the DSS and the data provided. In a context of trust, the process is unlikely to bog down in a debate on the quality of information but can go on to handle trade-offs and discuss preferences. If, on the contrary, the process must attempt to function in a context characterised by poor data quality, the result of this situation will be high costs for gathering new data and compiling existing information. If qualified researchers are not part of the process, poor data quality will then imply an additional need for expensive software and experts. In this case, a process convener might find it very expensive to use a DSS, and the application of a DSS might not be cost effective if alternative ways to fulfil the criteria and to resolve issues are available. Additionally, if the stakeholders do not trust the DSS, for example, because they view it as a black box that cannot accommodate values important to them, then the DSS might not help in handling trade-offs and identifying acceptable solutions.

A DSS can contribute to "challenging status quo and fostering creative thinking' by supporting the development 
of scenarios that depart from traditional forest management alternatives (e.g., by including values in addition to economic values in the [optimisation] models) and by helping to make the trade-offs between different values explicit. Using a DSS can, however, also restrict creative thinking if the system cannot handle all the kinds of information and values that characterise the situation and the actors affected. Forestry DSSs are usually quite inflexible. It may take months (or years) of programming to make changes to include new values. Depending on the system architecture, major changes may be virtually impossible.

A DSS can contribute to 'structured decision making process' by providing means for systematically dealing with different values relevant to the participants and by helping participants to focus on the relevant issues, thereby ensuring that no important issue is ignored. A challenge involved in using DSSs may be to maintain a focus on the participants and their values and to model the process according to their needs, rather than making them adapt their input to the demands of the DSS.

A DSS can improve transparency. The meaning of this term is that all the participants (and also any outsiders) understand why a certain alternative was chosen. Transparency is achieved by disclosing the information used and the procedure followed to produce the outcome. A major challenge associated with this disclosure process is that the DSS (or at least its principles) must be understandable to the participants so that it is not seen as a black box.

A DSS can enhance the 'independence and neutrality of the process' - that is, it can contribute to an unbiased process [management]-by disclosing the sources of the information inputs for the process. A DSS may also help to separate sources of information and to give more or less weight to information according to its quality. However, the challenge involved in this case is that no values should be excluded from the process on the grounds that the DSS is unable to handle them.

The inappropriate design or use of a DSS can also have a negative impact on these criteria. For example, a DSS can give participants the opportunity to influence the outcome by including their objectives and preferences. However, if the DSS is highly technical and the participants are not given sufficient support in providing input, then the outcome might be misleading. Additionally, a DSS can help to make the use of information more transparent. Yet, a DSS that allows manipulative forms of information handling can also be used to influence participants to support a particular decision. The remaining criteria have little or no relevance for DSSs because they depend more on other aspects of the participatory process related, for example, to organisation and communication.

One of the primary, if 'negative', results of this study is that fairly little information is available as a basis for a systematic assessment of existing DSSs against the evaluation criteria identified here. The information known to us, given on the FORSYS Wiki and in some papers (e.g., Reynolds 2005; Reynolds et al. 2008; Hiltunen et al. 2009), is not sufficient to allow a systematic assessment of the DSSs against these criteria.

DSS features addressing the criteria and the frequency of these features

After inspecting the DSSs on the FORSYS Wiki page and relevant literature, we relied on the expert knowledge of the authors (of this paper) to identify the features of DSSs that may help in making DSS useful to a participatory process. The features that we identified are as follows:

- group decision support,

- the possibility of including values other than timber production,

- the ability of the system to be sufficiently flexible to include non-traditional forest data and management options, for example, the possibility of including uneven-aged forests,

- tools for multi-criteria decision analysis.

Reasons that these features are helpful in addressing the criteria

A DSS consists of different features or components. Some of these features are very helpful for assessing the effects of a DSS in a participatory process because they have considerable potential to positively influence the abovementioned criteria. In the following section of the paper, we offer some suggestions about the links between the DSS features and the evaluation criteria. First, we suggest that all the features identified may positively influence the success criterion 'opportunity to influence outcome'. Multi-criteria decision analysis features particularly provide 'structure to the decision making process'. The criteria 'quality and selection of information' and 'challenging status quo and fostering creative thinking' can be addressed by the features that allow the inclusion of multiple values and that permit the inclusion of non-traditional forest data and management options. The inclusion of these additional items is significant because they are important for addressing relevant values and for promoting creative and constructive solutions. The features that allow the support of group decisions and the inclusion of multiple values also address the criterion independence and neutrality of the process' because they may help equalise the participants' influence or at least make inequalities visible. The features that permit the inclusion of multiple values and MCDA address 'transparency' by providing the means 
Table 3 Evaluation criteria, DSS features, and the criteria they address

\begin{tabular}{|c|c|c|c|c|c|c|}
\hline \multirow[t]{2}{*}{ DSS features } & \multicolumn{6}{|c|}{ Evaluation criteria } \\
\hline & $\begin{array}{l}\text { Opportunity } \\
\text { to influence } \\
\text { outcome }\end{array}$ & $\begin{array}{l}\text { Quality and } \\
\text { selection of } \\
\text { information }\end{array}$ & $\begin{array}{l}\text { Challenging status } \\
\text { quo and fostering } \\
\text { creative thinking }\end{array}$ & $\begin{array}{l}\text { Providing structure } \\
\text { to the decision- } \\
\text { making process }\end{array}$ & Transparency & $\begin{array}{l}\text { Independence } \\
\text { and neutrality of } \\
\text { the process }\end{array}$ \\
\hline Group decision support features & $\mathrm{X}$ & & & & $\mathrm{X}$ & $X$ \\
\hline $\begin{array}{l}\text { Possibilities to include other } \\
\text { values than timber production }\end{array}$ & $\mathrm{X}$ & $\mathrm{X}$ & $\mathrm{X}$ & & $\mathrm{X}$ & \\
\hline $\begin{array}{l}\text { Flexibility of system to include } \\
\text { non-traditional forest data and } \\
\text { management options }\end{array}$ & $X$ & & & & & $\mathrm{X}$ \\
\hline MCDA features & $X$ & & & $X$ & $X$ & \\
\hline
\end{tabular}

for backtracking a decision through the decision-making process. None of the DSS features explicitly address the criterion 'cost-effectiveness', but all may theoretically help to improve the process without making it more costly. However, in fact most DSS developers might not be overly concerned about the cost-effectiveness of the processes their systems are supposed to support. (For an overview of features and criteria, see Table 3). As the criterion of fairness is fairly complex and also intersects with other criteria, we do not evaluate the contribution of DSS features to the fulfilment of this criterion. One might also argue that a DSS might enhance the legitimacy and acceptance of outcomes of a participatory planning process if the DSS is seen as providing good scientific evidence in the decision-making process. To provide this evidence, however, should be expected from every DSS and does not have implications for its specific features in the context of participatory planning. For this reason we do not further elaborate on the criteria legitimacy and acceptance.

A review of the information on DSSs collected on the FORSYS Wiki indicates that few DSSs have been used in a participatory context. The majority of the currently used DSSs do not include means to handle group preferences. In many cases, it is possible to include only the preferences of one decision-maker. Only a few DSSs (e.g., HEUREKA, NED and MONSU) include variables that are not related to timber production. Only a few systems can be developed by the users (e.g., SIMO). The review of the FORSYS Wiki page and the literature also shows that only a handful of DSSs include tools for MCDA: Criterium DecisionPlus (AHP and SMART), DSD (pairwise comparisons and utility models), EMDS (linked to Criterium DecisionPlus), Heureka (AHP and direct point allocation), Mesta (acceptance threshold/border of approval), AFFOREST, NED, LMS, SADfLOR, and Woodstock.

Overall, these DSS features provide the potential for positive contributions to participatory planning processes. DSSs that do not include these features are relatively less capable of making such contributions.

\section{Discussion and conclusion}

We began by identifying the tension between deliberative approaches and computerised tools, and we concluded that this tension can be resolved. We identified eight relevant evaluation criteria for a successful participatory planning process that could be favourably influenced by a welldesigned DSS. Thus, we suggest that some features of DSSs can actually assist participatory planning. We found that in terms of the eight evaluation criteria identified, five particular features of DSSs are appropriate for supporting the success of participatory planning. However, these features are not common, and none of these features can address all of the criteria. Furthermore, we consider that a tool that would handle all of the criteria is not achievable for several reasons, particularly the trade-offs existing between criteria and the associated costs. These costs are mainly associated with programming and data collection, but they also result from organising the process to elicit and include stakeholder values in the development phase of a DSS.

These points will now be addressed in more detail. Developing existing systems to include features for, for example, group decisions or MCDA demands time and resources for programming. It is a challenge for technicians or researchers to program a tool that can match available data and the values of the stakeholders. For example, even if recreational values are included, a DSS may not be useful if it only handles traditional forestry data (such as standing timber volume, basal area, etc.). In addition, features for the inclusion of multiple values and non-traditional forest data and management are likely to be costly because they require the collection and compilation of new kinds of data. Additionally, most forest DSSs are quite inflexible in the sense that they must be modified by the developer because they are far too complex to be changed by the user. Furthermore, most forest DSSs are not open access. Consequently, we suggest that participatory modelling should be applied in the development of new DSS 
that are to be used in a participatory setting; i.e., that stakeholders should be involved in the development to make sure that their interests and types of values are likely to be included in the DSS as well as the factual knowledge they hold (Lawrence and Stewart 2011). This consideration is of particular relevance-and also poses a particular challenge-if the knowledge of stakeholders or users might change the 'functional' understanding of the system that the DSS embodies. However, the inclusion of stakeholders in the development of a DSS will demand time and resources and will also require adequate methodologies (Marques et al. 2011).

Even if stakeholders are involved in the development process, the high level of formality of DSSs means that there is a risk of neglecting certain types of information that some stakeholders might consider relevant. Relevant information can be neglected if the structure of the information does not match the structure required by the DSS. For example, information on aesthetics is only available in ordinal form, but a given DSS might not be able to handle ordinal data. Yet another example is that stakeholder preferences in many cases are uncertain or imprecise and that the DSS ideally should allow for uncertain or fuzzy data to model the preferences more realistically (Kangas et al. 2008; Munda 2006). Thus, even a well-working DSS with MCDA features might hinder fulfilment of the criteria 'creative thinking and challenging the status quo' if data, values, and other dimensions included in a DSS were to bias the result in a certain direction. This observation is also linked to the point above: a DSS might impose a structure on the decision-making process that might considerably narrow the possible space of decision outcomes (Hiltunen et al. 2009). Consequently, we do not expect that any of the features identified will in themselves foster creative thinking. However, it has been shown that the way they are used can foster this thinking (Mustajoki et al. 2011). This idea further supports the prevailing notion in the forestry literature that MCDA can be a promising tool to make forest planning more participatory (Kangas and Kangas 2005; Sheppard and Meitner 2005; Mendoza and Martins 2006).

In the context of SFM, we suggest that DSSs should include dimensions such as recreational use in a consequent manner. This suggestion implies that DSSs should be able to handle data on human use or activity levels, for example, the number of hikers, bikers, etc. at different spots or in different areas. This approach would allow the systematic inclusion of health and well-being, and therefore social dimensions, in participatory and tool-assisted forest management decisions. However, the inclusion of recreational data often implies the need to adjust models and tools to accommodate these new data. Indeed, the structure of these data might be different from that of the data that serve as inputs to a traditional forest DSS (Varma et al. 2000).

These considerations strongly suggest that major changes may be required in DSS models. However, it is not always possible to realise major changes of this sort in a cost-effective manner. Such changes imply that different kinds of values and data with different structure must be included in the model. The programming effort required to achieve this goal is simply too complex and costly in many cases. Thus, we suggest that complementary non-computerised tools should be used in an effort to fulfil some of the criteria that a DSS could theoretically address. This approach includes the assistance of a good facilitator, an important element in any participatory process, not only in processes that use DSSs.

If the aim of this effort is to find an appropriate combination of computerised and non-computerised tools and techniques, then it is critical to develop a procedure for the careful assessment of a DSS. Earlier creative applications have shown that a DSS and the information available from the DSS can be combined with or compared with local or expert knowledge (e.g., Kangas et al. 2000). Likewise, the results from a traditional forest DSS (like MELA) can be combined with a DSS specifically designed for group decision-making support (like MESTA) (e.g., Pykäläinen et al. 1999; Hiltunen et al. 2009). So far, however, no systematic procedure has been developed to appropriately combine computerised and non-computerised tools.

We also suggest that, even though the fulfilment of a criterion may potentially be improved by the use of a DSS, non-computerised tools can be at least as good. Thus, the great challenge is to find ways to combine non-computerised tools with computerised tools to address the relevant set of evaluation criteria in a specific planning situation.

Combining DSSs with non-computerised tools, limitations, and future research

We argue that someone, possibly the project leader or process convener, should assess the potentials and limitations of the DSS in question to plan its appropriate use in a process; that is, to clarify how it can be used in the given planning situation (given the aims of the planning process) and how it should be complemented by other available and non-computerised tools. The corresponding assessment procedure would imply using the evaluation criteria as a starting point for scrutinising the available DSS and its features. The assessment procedure would also need to plan how to address the criteria. The crucial point would be to decide which criteria were to be addressed with an available computerised tool and which criteria were best addressed by non-computerised tools or techniques. Figure 1 illustrates this principle of the complementary use of 


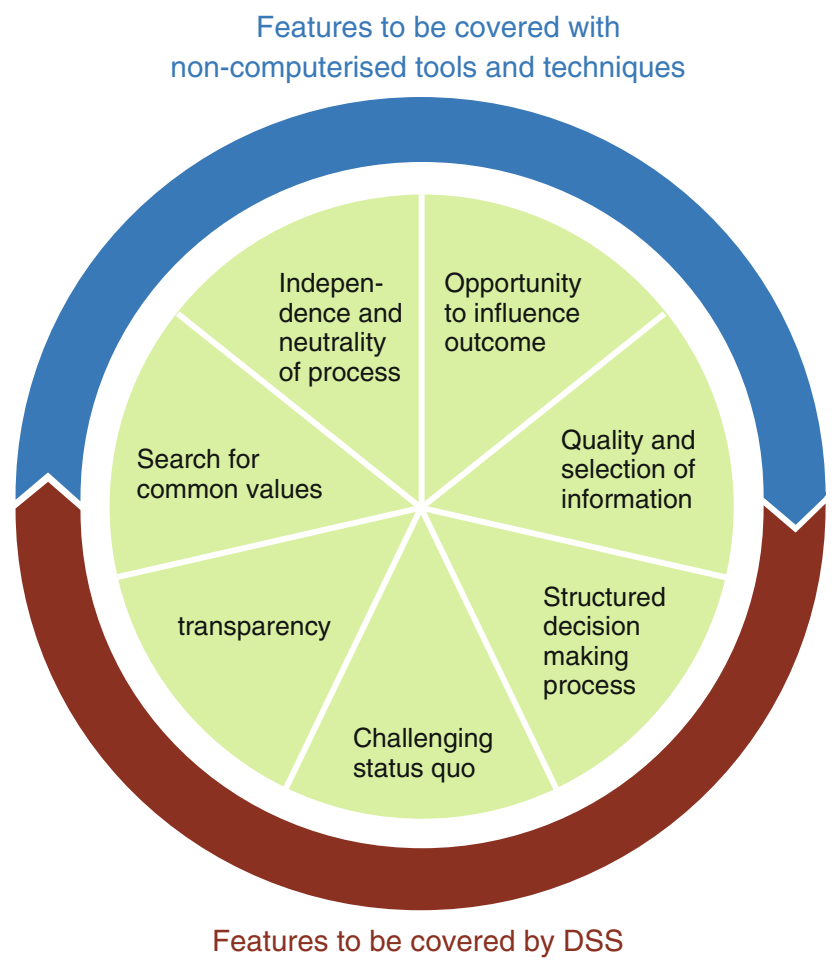

Fig. 1 Complementary use of computerised and non-computerised tools may improve the fulfillment of evaluation criteria. The tools should be chosen and adapted to the specific situation; in one case a computerised tool may be suitable, whereas in another case a noncomputerised tool may be more appropriate to address a certain criteria. Thus, the coverage of the arrows surrounding the criteria diagram may vary according to the demands of the situation

computerised and non-computerised tools. Some criteria are best addressed by the use of a DSS, whereas other criteria should be addressed by deliberative and participative tools and techniques. In general, all of the selected criteria may be addressed either by DSSs or by participative techniques. The most appropriate mix of analytical tools and deliberative techniques will depend on the specific situation, characterised by the stakeholders involved and the availability of time, resources, data, and computerised tools. The first attempts at the assessment of tools by using the concept of formality have appeared previously (Newig et al. 2008) and provide helpful insights for developing an assessment procedure for DSSs.

The main limitation of our analysis and suggestions is that they are based on an assessment of DSS features against evaluation criteria for participatory planning and not on actual applications or uses of DSSs in participatory planning processes. The reason for this discrepancy is that we lack information about the performance of DSSs in participatory processes. Our analysis relies on the information that we could extract from the FORSYS-wiki page and the literature known to us; consequently, some DSSs might have escaped our search process, but we still consider our overview fairly comprehensive. Future research should aim at assessing actual planning processes as a basis for the evaluation of participatory planning processes that use DSSs. As indicated above, we see the use of a given DSS as more relevant than its features for its positive or negative contribution to a successful participatory planning process. However, our findings so far are that - given available information-the assessment of the features is feasible, whereas the assessment of the use of DSSs with these features is not.

Further research should focus on the use of DSSs in participatory planning. Such research should provide guidelines for assessing a given DSS and thereby identifying the possibilities for using it in a participatory planning process. The results of the research should help to indicate how a given DSS can be appropriately complemented by other, non-computerised tools and techniques. Actual participatory planning processes that include the use of existing DSSs should be assessed in case studies. The intermediate aim of this research would be to enable project leaders to make better decisions about how to combine a DSS with other techniques, given a particular DSS, available data, and the rationale or motivation behind the planning process. Research on computerised tools should be combined with research on non-computerised tools and techniques (for an evaluation of non-computerised tools, see, for example, Lynam et al. 2007). Another line of research would be to investigate why DSSs are not used even though circumstances would allow for their application (Stewart et al. 2010).

Overall, using a carefully chosen combination of DSS and deliberative approaches will enhance the possibility of achieving SFM because the combination will facilitate not only the modelling and forecasting of economic and ecological outcomes but also the incorporation of stakeholder values.

Acknowledgments Susanne Menzel acknowledges financial support by the Competence Center Environment and Sustainability (CCES) of the Swiss Federal Institute of Technology (ETH) Domain. Eva-Maria Nordström acknowledges financial support from Future Forests, a multi-disciplinary research programme supported by the Foundation for Strategic Environmental Research (MISTRA), the Swedish Forestry Industry, the Swedish University of Agricultural Sciences (SLU), Umeå University, and the Forestry Research Institute of Sweden. This article is a result of the Working Group on participatory processes of the COST-action FP0804-Forest Management Decision Support Systems (FORSYS). The FORSYS COST-action also provided financial support for a short-term scientific mission in which the article was developed.

\section{Appendix 1: Literature included in the review of criteria}

Abelson, J, Forest, P G, Eyles, J, Smith, P, Martin, E, Gauvin, F P (2003) Deliberations about deliberative methods: issues in the design and evaluation of public 
participation processes. Social Science \& Medicine Vol. 57 pp. 239-251.

Beierle, T, Konisky, D (2001) What are we gaining from stakeholder involvement? Observations from Environmental Planning in the Great Lakes. Environment and Planning C, Government and Policy pp. 515-527.

Beierle, T, Cayford, J (2002) Democracy in practice: public participation in environmental decisions. Resources for the future, Washington D. C.

Beierle, T C (1998) Public Participation in Environmental Decisions: An Evaluation Framework Using Social Goals. Discussion paper, i-31.

Bellamy, J A, McDonald, G T, Syme, G J, Butterworth, J E (1999) Evaluating integrated resource management. Society and Natural Resources Vol. 12 pp. 337-353.

Blackstock, K L, Kelly, G J, Horsey, B L (2007) Developing and applying a framework to evaluate participatory research for sustainability. Ecological Economics Vol. 60 pp. 726-742.

Blahna, D, Yonts-Shepard, S (1989) Public involvement in resource planning: Toward bridging the gap between policy and implementation. Society and Natural Resources Vol. 2 pp. 209-227.

Cheng, A S, Mattor, K M (2006) Why won't they come? Stakeholder perspectives on collaborative national forest planning by participation level. Environmental Management Vol. 38 pp. 545-561.

Chess, C, Purcell, K (1999) Public participation and the environment: Do we know what works? Environmental Science \& Technology Vol. 33 pp. 2685-2692.

Duinker, P N (1998) Public participation's promising progress: advances in forest decision-making in Canada. Commonwealth Forestry Review Vol. 77 pp. 107-112.

Germain, R H, Floyd, D W, Stehman, S V (2001) Participant perceptions of the Forest Service's public participation process. Journal of Forest Policy and Economics Vol. 3 pp. 113-124.

Hamersley Chambers, F, Beckley, T (2003) Public involvement in sustainable boreal forest management. Towards sustainable management of the boreal forest, Burton P J, Messier C, Smith D W and Adamowicz W L (eds). (2003) NRC Research Press, Ottawa, pp. 113-154.

Innes, J E (2004) Consensus Building: Clarification for the Critics. Planning Theory Vol. 3 pp. 5-20.

Innes, J E, Booher, D E (1999) Consensus building and complex adaptive systems - A framework for evaluating collaborative planning. Journal of the American Planning Association Vol. 65 pp. 412-423.
McCool, S F, Guthrie, K (2001) Mapping the dimensions of successful public participation in messy natural resources management situations. Society \& Natural Resources Vol. 14 pp. 309-323.

Moote, M A, McClaran, M P, Chickering, D K (1997) Theory in practice: Applying participatory democracy theory to public land planning. Environmental Management Vol. 21 pp. 877-889.

Rauschmayer, F, Risse, N (2005) A framework for the selection of participatory approaches for SEA. Environmental Impact Assessment Review Vol. 25 pp. 650-666.

Renn, O, Webler, T, Wiedemann, P (1995) A Need for Discourse on Citizen Participation: Objectives and Strucutre of the Book. Fairness and Competence in Citizen Participation: Evaluating Models for Environmental Discourse, Renn O, Webler T and Wiedemann P (eds). (1995) Kluwer Academic Publishers, Dordrecht, NL, pp. 1-15.

Rowe, G, Frewer, L J (2000) Public participation methods: A framework for evaluation. Science Technology \& Human Values Vol. 25 pp. 3-29.

Sheppard, S R J, Meitner, M (2005) Using multi-criteria analysis and visualisation for sustainable forest management planning with stakeholder groups. Forest Ecology and Management Vol. 207 pp. 171-187.

Sheppard, S R J, Achiam, C M, Jeffery, B (2004) Social and collaborative forestry - public participation in forest decision making. Elsevier, Oxford.

Shindler, B, Neburka, J (1997) Public participation in forest planning - 8 attributes of success. Journal of Forestry Vol. 95 pp. 17-19.

Susskind, L, Cruikshank, J (1987) Breaking the Impasse. Consensual Approaches to Resolving Public Disputes. Basic Books.

Tuler, S, Webler, T (1999) Voices from the forest: What participants expect of a public participation process. Society \& Natural Resources Vol. 12 pp. 437-453.

Webler, T, Tuler, S, Krueger, R (2001) What is a good public participation process? Five perspectives from the public. Environmental Management Vol. 27 pp. 435-450.

Wittmer, H, Rauschmayer, F, Klauer, B (2006) How to select instruments for the resolution of environmental conflicts? Land Use Policy Vol. 23 pp. 1-9.

\section{Appendix 2}

See Table 4. 
Table 4 List of criteria definitions

\begin{tabular}{ll}
\hline Evaluation criteria & Criteria definition
\end{tabular}

Fairness

Relationships and social capital building

Structured group interaction

Facilitation of constructive individual/ group behaviour

Representation

Opportunity to influence outcome

Quality and selection of information Cost-effectiveness

Accessibility of process

Adequate resources

Opportunity to influence process design

Challenging status quo and fostering creative thinking

Structured decision-making process

Clear mandate and goals

Transparency

Acceptance of outcome

Accountability

Independence and neutrality of process

Legitimacy

Search for common values
Access to the process and power to influence process and outcomes (Webler et al. 2001)

Referring to issues of social capital through new and existing social networks developed during the process/project, for example, trust, reciprocity and collaboration (Blackstock et al. 2007)

Relates to principles about the structural characteristics of the process; for example, planning of meeting-time, location, "physical arrangements". Locus of control is with the planner of the process (Tuler and Webler 1999).

Relates to principles about personal behaviour of individuals taking part in the process; for example, ground rules (Tuler and Webler 1999)

Referring to the spread of representation from affected interests; including how legitimate the representation is seen to be; the diversity of views is important not just that representatives from different groups are invited (Blackstock et al. 2007)

Referring to the participant's opportunity to influence (enough time; involved early enough; access to policy makers and leaders; organisational structure) (Blackstock et al. 2007)

Giving people the opportunity to express their preferences and values (co-authors)

Referring to the adequacy, quality and quantity of information provided (Blackstock et al. 2007)

Referring to the improvements created through the process in relation to the costs accrued (Blackstock et al. 2007)

The issue of physically getting people present and involved in deliberative settings (Tuler and Webler 1999)

Public participants have access to the appropriate resources to enable them to successfully fulfil their brief (Rowe and Frewer 2000).

Sufficient time and supporting technical resources. PP takes time and organisers must ensure provision of sufficient technical resources to allow participants to formulate sound opinions based on timely and reliable information (Duinker 1998).

The public is involved as early as possible in the process as soon as value judgments become salient (Rowe and Frewer 2000).

The decision-making process is clearly structured, with inclusion of stakeholders in the process design and transparency on how final decisions will be reached (Sheppard and Meitner 2005).

Process encourages questioning the status quo and encourages the imagination of alternative futures (Innes and Booher 1999).

The participatory process uses appropriate mechanisms for structuring and displaying the decisionmaking process (Rowe and Frewer 2000)

Expectations towards participants are clearly laid out at the beginning of any process (Duinker 1998)

The nature and scope of the participation task are clearly defined; scope, expected output and mechanisms for the procedure are defined (Rowe and Frewer 2000).

Referring to both internal, whereby participants understand how decisions are made; and external, whereby observers can audit the process (Blackstock et al. 2007)

Social and political acceptability (McCool and Guthrie 2001)

Groups and individuals interested in or affected by public land decisions report that the resultant plan addresses their needs, concerns, and values, and they will not appeal it (Moote et al. 1997)

Referring to whether the representative's core constituencies are satisfied, including expectations (Blackstock et al. 2007)

The process is conducted in an independent, unbiased manner. Participants are free to conduct themselves in a voluntary and self-directed manner without coercion, and process management is neutral. The process seeks the common good, not just accommodating specific interests (Sheppard et al. 2004).

Referring to whether the outcomes and process are accepted as authoritative and valid (Blackstock et al. 2007)

A participatory decision-making process places strong emphasis on the value-based character of a policy dispute and the mechanisms by which it is managed (Webler et al. 2001). 


\section{References}

Allen GM, Gould EM (1986) Complexity, wickedness, and public forests. J For 84:20-23

Ananda J, Herath G (2003a) Incorporating stakeholder values into regional forest planning: a value function approach. Ecol Econ 45(1):75-90

Ananda J, Herath G (2003b) The use of analytic hierarchy process to incorporate stakeholder preferences into regional forest planning. For Policy Econ 5(1):13-26

Beierle T, Cayford J (2002) Democracy in practice: public participation in environmental decisions. Resources for the Future, Washington

Blackstock KL, Kelly GJ, Horsey BL (2007) Developing and applying a framework to evaluate participatory research for sustainability. Ecol Econ 60(4):726-742

Castañeda F, Palmberg-Lerche C, Vuorinen P (2001) Criteria and indicators for sustainable forest management: a compendium. Forest management working paper, vol 5. Forest Resources Development Service, Forest Resources Division, FAO, Rome

Checkland P (1981) Systems thinking, systems practice. Wiley, New York

Cubbage F, Harou P, Sills E (2007) Policy instruments to enhance multi-functional forest management. For Policy Econ 9:833-851

Davis LS, Johnson KN, Bettinger PS, Howard TE (2001) Forest management, 4th edn. McGraw-Hill, New York

Eyvindson K, Kangas A, Kurttila M, Hujala T (2010) Using preference information in developing alternative forest plans. Can J For Res-Rev Can Rech For 40(12):2398-2410

Fiorino D (1989) Environmental risk and democratic process: a critical review. Colum J Envtl L 14:501-547

Funtowicz SO, Ravetz JR (1993) Science for the post-normal age. Futures 25(7):739-755

Gibbons M (1999) Science's new social contract with society. Nature 402(6761):C81-C84

Hahn WA, Knoke T (2010) Sustainable development and sustainable forestry: analogies, differences, and the role of flexibility. Eur J For Res 129(5):787-801

Hiltunen V, Kangas J, Pykäläinen J (2008) Voting methods in strategic forest planning-experiences from Metsähallitus. For Policy Econ 10(3):117-127

Hiltunen V, Kurttila M, Leskinen P, Pasanen K, Pykäläinen J (2009) Mesta: an internet-based decision-support application for participatory strategic-level natural resources planning. For Policy Econ 11(1):1-9

Kangas J, Kangas A (2005) Multiple criteria decision support in forest management-the approach, methods applied, and experiences gained. For Ecol Manag 207(1-2):133-143

Kangas J, Loikkanen T, Pukkala T, Pykäläinen J (1996) A participatory approach to tactical forest planning. Acta For Fenn 251:1-24

Kangas J, Store R, Leskinen P, Mehtatalo L (2000) Improving the quality of landscape ecological forest planning by utilising advanced decision-support tools. For Ecol Manag 132(2-3): $157-171$

Kangas A, Kangas J, Pykäläinen J (2001) Outranking methods as tools in strategic natural resources planning. Silva Fenn 35(2): 215-227

Kangas A, Kangas J, Kurttila, M (2008) Decision support for forest management. Managing forest ecosystems, vol 16. Springer, Dordrecht

Laukkanen S, Palander T, Kangas J (2004) Applying voting theory in participatory decision support for sustainable timber harvesting. Can J For Res-Rev Can Rech For 34(7):1511-1524
Lawrence A, Stewart A (2011) Sustainable forestry decisions: on the interface between technology and participation. Math Comput For Nat Res Sci 3:42-52

Lynam T, de Jong W, Sheil D, Kusumanto T, Evans K (2007) A review of tools for incorporating community knowledge, preferences, and values into decision making in natural resources management. Ecol Soc 12(1):15

Maness T, Farrell R (2004) A multi-objective scenario evaluation model for sustainable forest management using criteria and indicators. Can J For Res-Rev Can Rech For 34(10):2004-2017

Marques AF, Borges JG, Sousa P, Pinho AM (2011) An enterprise architecture approach to forest management support systems design: an application to pulpwood supply management in Portugal. Eur J For Res. doi:10.1007/s10342-011-0482-8

Matthies M, Giupponi C, Ostendorf B (2007) Environmental decision support systems: current issues, methods and tools. Environ Model Softw 22(2):123-127

McCool SF, Guthrie K (2001) Mapping the dimensions of successful public participation in messy natural resources management situations. Soc Nat Resour 14(4):309-323

Mendoza GA, Martins H (2006) Multi-criteria decision analysis in natural resource management: a critical review of methods and new modelling paradigms. For Ecol Manag 230(1-3):1-22

Munda G (2006) A NAIADE based approach for sustainability benchmarking. IJETM 6:6-78

Mustajoki J, Saarikoski H, Marttunen M, Ahtikoski A, Hallikainen V, Helle T, Hyppönen M, Jokinen M, Tuulentie S, Varmola M, Vatanen E, Yli-Sirniö A-L (2011) Use of decision analysis interviews to support the sustainable use of the forests in Finnish Upper Lapland. J Environ Manag 92:1550-1563

Newig J, Gaube V, Berkhoff K, Kaldrack K, Kastens B, Lutz J, Schlußmeier B, Adensam H, Haberl H (2008) The role of formalisation, participation and context in the success of public involvement mechanisms in resource management. Syst Pract Action Res 6:423-441

Nordström E-M, Eriksson LO, Öhman K (2010) Integrating multiple criteria decision analysis in participatory forest planning: experience from a case study in Northern Sweden. For Policy Econ 12(8):562-574

Nowotny H, Scott P, Gibbons M (2001) Re-thinking science: knowledge production in an age of uncertainty. Polity, Cambridge

Pykäläinen J, Kangas J, Loikkanen T (1999) Interactive decision analysis in participatory strategic forest planning: experiences from state owned boreal forests. J For Econ 5(3):341-364

Reynolds KM (2005) Integrated decision support for sustainable forest management in the United States: fact or fiction? Comput Electron Agric 49(1):6-23

Reynolds KM, Twery M, Lexer MJ, Vacik H, Ray D, Shao G, Borges JG (2008) Decision support systems in forest management. In: Burstein F, Holsapple CW (eds) Handbook on decision support systems 2. Springer, Berlin, pp 499-534

Rowe G, Frewer LJ (2000) Public participation methods: a framework for evaluation. Sci Technol Hum Values 25(1):3-29

Rowe G, Frewer LJ (2004) Evaluating public-participation exercises: a research agenda. Sci Technol Hum Values 29:512-557

Sheppard SRJ, Meitner M (2005) Using multi-criteria analysis and visualisation for sustainable forest management planning with stakeholder groups. For Ecol Manag 207:171-187

Stewart A, Lawrence A, Edwards D (2010) Uptake of Decision Support Systems in the forest sector in Great Britain-scoping report. Forestry Commission. http://www.forestry.gov.uk/fr/ dssuptake. Accessed 18 June 2011

Stirling A (2008) Opening Up" and "Closing down. Sci Technol Hum Values 33(2):262-294 
The Montréal Process (2009) Criteria and indicators for the conservation and sustainable management of temperate and boreal forests. Montréal Process Working Group. http://www.rinya. maff.go.jp/mpci/meetings/an-6.pdf. Accessed 18 June 2011

UN (1992) Non-legally binding authoritative statement of principles for a global consensus on the management, conservation and sustainable development of all types of forests. United Nations, New York
Varma VK, Ferguson I, Wild I (2000) Decision support system for the sustainable forest management. For Ecol Manag 128(1-2):49-55

Wittmer H, Rauschmayer F, Klauer B (2006) How to select instruments for the resolution of environmental conflicts? Land Use Policy 23(1):1-9

Xu Z, Bengston DN (1997) Trends in national forest values among forestry professionals, environmentalists, and the news media, 1982-1993. Soc Nat Resour 10(1):43-59 